\title{
Environmental Sustainability—necessary for survival
}

\author{
Naveen Kumar Arora ${ }^{1}$
}

Published online: 26 June 2018

(c) Society for Environmental Sustainability 2018

Environmental sustainability is one of the biggest issues faced by the mankind at present. Increasing population along with tremendous escalation in anthropogenic activities has raised several questions on the sustainability of natural resources on our planet. No part of the Earth is now untouched by the effect of human activities or pollution. Ever increasing human population and increment in per capita consumption has put great constraint on the natural resources. In addition to this, urbanization, industrialization and modern agricultural practices have polluted the water resources, air and soil all around the globe. The natural resources are thus not only being over-exploited but also becoming contaminated with toxic chemicals making it difficult for the survival of future generations.

The ever increasing emission of green house gases is showing far reaching impact on the blue planet and according to estimates of various agencies such as United States Development Authority (USDA) and Organization for Economic Cooperation and Development (OECD) this will result in rise in temperature by $02{ }^{\circ} \mathrm{C}$ by 2050 . This has and will further change the face of the earth. Due to the impact of global warming, glaciers and polar ice is melting at rates 2-3 times higher in comparison to last century. According to estimates, Earth at present is going through one of the biggest biodiversity loss phase, the impact of which is unforeseen and unpredictable. As per a United Nations report the human-caused rate of extinction of species of both plants and animals at present is hundreds of times higher than the natural rate in the past and as the situation is turning out it can be thousands of times higher in near future. As an example it is estimated that the rate at which coral reefs are depleting, they will be completely wiped out in very near future and with them several other species will also become extinct.

Naveen Kumar Arora

nkarora.bbau@gmail.com

1 Department of Environmental Science, Babasaheb Bhimrao Ambedkar University, Lucknow, Uttar Pradesh, India
Targeting short term gains, humans have destroyed the natural systems with great pace. But it is difficult to estimate the impact of anthropogenic activities on ecology, in term of economics and even the survivability rate of different life forms on Earth. Although the technology has also advanced at a great pace but still we have hungry people who do not get enough calories to grow normally or even survive. We have issues of availability of potable water, pure air to breathe and ever increasing problem of land degradation. Saline soils are going to increase by $50 \%$ up to 2050 and land degradation has affected almost every country of the world. Human population is going to produce 27 billion tones of municipal solid waste by 2050 which would require great input of technology to manage and role of microorganisms will be immense. Amount of non-degradable wastes is increasing by the minute and some of the dangerous recalcitrants are accumulating in the food chains and are the cause of contamination of natural resources and extinction of species apart from causing harm to the humans. As per recent report published in Scientific Reports a mass of plastic waste named as "Great Pacific Garbage Patch" approximately 1.6 million $\mathrm{km}^{2}$ in size $\sim$ twice the size of Texas, is floating on the surface of Pacific ocean. Plastics are also accumulating on land and in water bodies at an unprecedented rate and we need to find a quick alternative for these harmful creations of humans.

It is very important to assess the impact of human activities on the local ecosystems and the planet as a whole on a regular basis. Use of latest technologies and tools although help in the assessment of the situation but the need is to find green solutions as well. Biotechnological approaches and green technologies are providing the solutions to these problems. Scientists are in process of developing green fuels and novel energy sources which could replace petroleum products and provide green energy so as to cut down the emission of green house gases. Similarly management of pollutants, organic wastes and biodegradation of contaminated sites is being achieved by the help of biotechnological tools. Bioremediation is also a very important task which is being targeted for replenishing the polluted habitats using 
microorganisms and phytoremediation techniques. Food security is a big issue faced by the mankind. Sustainable agriculture has still not been achieved, as dangerous and harmful agro-chemicals rule the market throughout the globe and have caused great harm to the ecosystems worldwide. To achieve food security through sustainable means by maintaining the fertility and microbial diversity of the soil is still a challenge. Sustainable agriculture and organic farming are the biggest targets for the scientists in the future and already great results have been reported wherein chemicals are being replaced by biostimulants and biopesticides. Management of stress in crops and enhancement of productivity of marginal, fragile and extreme habitats is also the target of the future which has to be achieved using biological approaches. This will not only lead to food security but also to sustainability of the agro-ecosystems.

Environmental sustainability is thus one of the biggest challenge and most important targets of the present times. It is the major attention area for researchers, academicians, scholars, governments and non-government organizations involving individuals, communities, countries, continents and the globe as whole. Environmental sustainability is the key strategy against the backdrop of the growth of human population and the rampant exploitation of environment by humans. The underlying concern of modern society is that while today people are enjoying the comforts of economic development, the future generations are on the verge of confronting scarce natural resources and polluted environment and it is our most important responsibility to leave the planet as a self sustainable system providing equal opportunities of survival not only to our future generations but also to all other species co-habiting with us.

The journal "Environmental Sustainability" will cover all such issues focusing on tackling the environmental problems by biological means. Among the contemporary array of topics, this journal will cover: sustainable agriculture, biodegradation and bioremediation, stress management, plant-microbe interactions, organic food production, environmental microbiology, pollution management and sustainable management of fragile habitats such as Polar Regions, glaciers, rain forests, oceans etc. which provide so much support to the ecosystems where humans thrive. The journal will be a platform for the researchers and scholars working in the areas of environmental science, microbiology, biotechnology, biodiversity conservation, sustainable agriculture, stress management in crops and others related to environmental sustainability, to showcase their work and ideas to the world so as to use it for a better future for all life forms on Earth.

The journal will promote the work based on latest technologies and inter-disciplinary approaches for achieving the targets of environmental sustainability. Research from micro or even nano-level involving microbiomes, metagenomes, at molecular and biochemical levels to nanotechnology and nanoparticles, to those interfacing physico-chemical and biological systems and to the ones involving satellite imaging, geo-mapping, etc. can be integrated for achieving the sustainability of the environment.

The journal is the copyright of the "Society for Environmental Sustainability" which aims to achieve the targets of environmental sustainability through spread of quality research and knowledge. The target of the Society is not only the scientific community but also to ignite the young minds so as to inculcate in them the idea of sustainability and giving equal opportunities of survival to all the living creatures on the earth.

The inaugural issue of the journal "Environmental Sustainability" covers research articles from around the globe addressing to the theme of the journal. Editorial team of the journal is very much familiar with the quality issues of the articles to be published in this journal, hence to overcome any ambiguity and maintain the excellence the manuscripts are critically reviewed by experts worldwide. Any critical reviews regarding the burning issues related to environment and its sustainability or novel research ideas correlated to the same are welcome from the researchers. We also invite societies/bodies, organizations, conference organizers in the area of environmental sustainability to contribute articles, ideas, or propose special thematic sections/issues of the journal.

Editor in Chief would like to thank all the members of the Editorial Board of the Journal for providing their precious time and whole hearted support because of which the first issue of the Journal will see the light of the day. Society and Editor in Chief are also thankful to Springer and its team for the endless support and encouragement.

Naveen Kumar Arora Editor in Chief 